\title{
Effect of surface treatments on push-out bond strength of calcium silicate-based cements to fiber posts
}

\author{
Amr M. Elnaghy ${ }^{1 *}$, Ayman Mandorah², Ali H. Hassan ${ }^{3,4}$, Alaa Elshazli ${ }^{1}$ and Shaymaa Elsaka ${ }^{4,5}$
}

\begin{abstract}
Background: To evaluate the effect of surface treatments on the push-out bond strength of Biodentine (BD) and white mineral trioxide aggregate (WMTA) to fiber posts.

Methods: Two brands of fiber posts were used: Reblida post; RP and RelyX post; RX. Each type of post ( $n=80 / g r o u p)$ was divided into four groups ( $n=20 /$ group) and exposed to surface treatment as follows: Control (no treatment), sandblasting (SB), hydrofluoric acid (HF), and $\mathrm{TiF}_{4} 4 \mathrm{wt} / \mathrm{v} \%$. Each group was further subdivided into two subgroups ( $n=10 /$ subgroup) based on the type of CSCs used as follows: Subgroup A: BD and Subgroup B: WMTA. Push-out bond strength of BD and WMTA to glass fiber posts was assessed. Data were statistically analyzed using three-way ANOVA and Tukey's test. A Weibull analysis was performed on the push-out bond strength data.
\end{abstract}

Results: BD showed higher bond strength than WMTA $(P<0.001)$. The push-out bond strength for posts treated with TiF4 $4 \mathrm{wt} / \mathrm{v} \%$ showed greater bond strength than the other surface treatments $(P<0.05)$. The BD/RP-TiF $44 \mathrm{wt} / \mathrm{v} \%$ showed the greater characteristic bond strength $\left(\sigma_{0}\right)(15.93)$ compared with the other groups. Surface treatments modified the surface topography of glass fiber posts.

Conclusions: The BD/RP- $\mathrm{TiF}_{4} 4 \mathrm{wt} / \mathrm{v} \%$ showed greater bond strength compared with the other groups. The $\mathrm{TiF}_{4} 4$ $\mathrm{wt} / \mathrm{v} \%$ surface treatment enhanced the bond strength of BD and WMTA to glass fiber posts than the other treatments. Surface treatment of fiber post with $\mathrm{TiF}_{4} 4 \mathrm{wt} / \mathrm{v} \%$ could be used to improve the bond strength with calcium silicatebased cements.

Keywords: Biodentine, Fiber post, Push-out bond strength, Surface treatments, Titanium tetrafluoride

\section{Background}

Calcium silicate-based cements (CSCs) revealed favorable clinical outcomes with different clinical applications [1-3]. Biodentine (BD; Septodont, Saint Maur des Faussés, France) and white mineral trioxide aggregate (WMTA) are CSCs that were used for different applications in endodontic treatment including pulp capping, repair of root perforations, pulpotomies, apical barrier,

\footnotetext{
*Correspondence: aelnaghy@mans.edu.eg

1 Department of Endodontics, Faculty of Dentistry, Mansoura University, Mansoura 35516, Egypt

Full list of author information is available at the end of the article
}

regenerative endodontics, and obturation of the entire root canal space [4-9]. MTA CSCs materials have certain limitations, including long setting time, discoloration of teeth, and difficulty in handling lead to the development of different CSCs to overcome these disadvantages [10-12].

One of the applications of CSCs is the treatment of non-vital immature permanent teeth [4]. This procedure is established by disinfection of root canal, placement of apical barrier together with root-filling materials [13]. The fracture resistance of simulated immature permanent teeth used BD with fiber post 
was compared with different canal filling materials [4]. It was suggested that BD combined with fiber post might reinforce the immature teeth with an apical BD plug [4]. Fiber posts improved the fracture resistance of the tooth because their flexural modulus mimic to that of dentin $[4,7,14-17]$. This biomimetic characteristic enhances the stress distribution which decreases the incidence of root fracture, the most critical form of failure [18-20].

Surface treatments had been suggested to improve the adhesion properties between bi-materials interface, by providing micromechanical and chemical retention between different constituents [21, 22]. Various surface treatments had been applied to enhance the bond strength between the fibre post and other restorative materials as composite core [22] and resin cements $[19,23]$ including sandblasting, silane coupling agent, and acid etching agents [19, 22-24].

The adhesion between the BD and fiber post was not evaluated. It is important to enhance bonding between $\mathrm{BD}$ and fiber post to reinforce the root canal as in cases of non-vital immature permanent teeth [4]. Consequently, the aim of this study was to assess different surface treatments on the push-out bond strength of BD and WMTA to different systems of glass fiber posts. The null hypotheses tested of were that: (1) Different surface treatments would not affect the adhesion between fiber post and CSCs materials; (2) Different type of posts would not present difference on adhesion regardless the surface treatments, and (3) Different CSCs materials would not affect the adhesion of the fiber post regardless the surface treatments.

\section{Methods}

The sample size determination was performed for pushout bond strength test using GPower v3.1.3 software (University of Düsseldorf; Düsseldorf, Germany). A power analysis revealed that a sample size of 50 specimens per subgroup was found to meet the constraints of $\alpha=0.05$ and power $=0.95$.

\section{Push-out bond strength}

Two brands of glass fiber posts were used: Reblida post (RP; size \# $\varnothing 1.5$, VOCO, Cuxhaven, Germany) and RelyX post (RX; size \# 2, 3 M ESPE, St. Paul, MN, USA). Materials used in this study are presented in Table 1. Each type of post $(n=80)$ was divided into four groups $(\mathrm{n}=20 /$ group$)$ and exposed to the surface treatment as follows:

Group 1: control (C); no treatment.

Group 2: sandblasting (SB); the specimens were treated with a tribochemical silica-coated (CoJet system; $3 \mathrm{M}$ ESPE) with $30 \mu \mathrm{m}$ aluminum oxide particles from a distance $10 \mathrm{~mm}$ at 2.5 bar pressure for $15 \mathrm{~s}$.

Group 3: hydrofluoric acid (HF); the specimens were treated with 9\% HF (Ultradent Porcelain Etch, Ultradent Products, South Jordan, UT, USA) for $1 \mathrm{~min}[23,25]$.

Group 4: titanium tetrafluoride $\left(\mathrm{TiF}_{4}\right)$; the specimens were immersed in $\mathrm{TiF}_{4} 4 \mathrm{wt} / \mathrm{v} \%$ (Sigma Aldrich, Saint Louis, MO, USA) solution for 4 min [23].

The specimens that were treated with $\mathrm{HF}$ and $\mathrm{TiF}_{4}$ $4 \mathrm{wt} / \mathrm{v} \%$ were ultrasonically cleaned in distilled water for $1 \mathrm{~min}$ and then air-dried. Each group was further

Table 1 Materials that used in this study

\begin{tabular}{|c|c|c|c|c|}
\hline Material & Product & Composition & Lot number & Manufacturer \\
\hline \multirow[t]{2}{*}{ Fiber post } & Reblida post Size \# Ø 1.5 & $70 \%$ glass fiber, $10 \%$ filler, $20 \%$ UDMA & 1143115 & VOCO, Cuxhaven, Germany \\
\hline & RelyX post Size \# 2 & $\begin{array}{l}\text { Glass fiber reinforced composite, meth- } \\
\text { acrylate resin }\end{array}$ & 173421109 & 3 M ESPE, St. Paul, MN, USA \\
\hline \multirow[t]{3}{*}{ Surface treatment } & Sandblasting (CoJet system) & $\begin{array}{l}\text { CoJet-Sand: Aluminum trioxide parti- } \\
\text { cles coated with silica, particles size: } \\
30 \mu \mathrm{m}\end{array}$ & 625642 & 3 M ESPE, St. Paul, MN, USA \\
\hline & Hydrofluoric acid & Buffered $9 \%$ hydrofluoric acid & BCG4P & $\begin{array}{l}\text { Ultradent Porcelain Etch, Ultradent } \\
\text { Products, South Jordan, UT, USA }\end{array}$ \\
\hline & Titanium tetrafluoride & Titanium tetrafluoride $4 \mathrm{wt} / \mathrm{v} \%$ & MKBN0100V & Sigma Aldrich, Saint Louis, MO, USA \\
\hline \multirow[t]{2}{*}{$\begin{array}{l}\text { Calcium silicate- } \\
\text { based cements }\end{array}$} & Biodentine & $\begin{array}{l}\text { Powder: Tricalcium silicate, Dicalcium } \\
\text { silicate, Calcium carbonate, Zirconium } \\
\text { dioxide, Iron oxideLiquid: Calcium } \\
\text { chloride, Hydrosoluble polymer }\end{array}$ & B18542A & $\begin{array}{l}\text { Septodont, Saint Maur des Faussés, } \\
\text { France }\end{array}$ \\
\hline & White mineral trioxide aggregate & $\begin{array}{c}\mathrm{SiO}_{2}, \mathrm{~K}_{2} \mathrm{O}, \mathrm{Al}_{2} \mathrm{O}_{3}, \mathrm{Na}_{2} \mathrm{O}, \mathrm{Fe}_{2} \mathrm{O}_{3}, \mathrm{SO}_{3}, \mathrm{CaO}, \\
\mathrm{Bi}_{2} \mathrm{O}_{3}, \mathrm{MgO} \text {. Insoluble residues of } \mathrm{CaO} \text {, } \\
\mathrm{KSO}_{4}, \mathrm{NaSO}_{4} \text {, and crystalline silica }\end{array}$ & 45732 & $\begin{array}{l}\text { PD MTA White; Produits Dentaires SA, } \\
\text { Vevey, Switzerland }\end{array}$ \\
\hline
\end{tabular}


subdivided into two subgroups ( $\mathrm{n}=10 /$ subgroup) based on the type of CSCs used as follows:

Subgroup A: BD (Septodont, Saint Maur des Faussés, France).

Subgroup B: WMTA (PD MTA White; Produits Dentaires SA, Vevey, Switzerland).

A sticky wax was used to position the post perpendicularly on a square plastic plate. Then, the post was surrounded by a cylindrical plastic matrix $(12 \mathrm{~mm}$ height $\times 10 \mathrm{~mm}$ diameter) [22, 24]. The cylinder was filled with the CSCs using a MAP system (MAP One, Produits Dentaires SA, Vevey, Switzerland). The specimens were stored at $37^{\circ} \mathrm{C}$ and $100 \%$ humidity for $48 \mathrm{~h}$. The specimens were exposed to 10,000 thermocycles in distilled water between 5 and $55^{\circ} \mathrm{C}$ with 5 -s transfer time and 30-s dwell time $[4,7,26]$.

After that, the straight portion $(10 \mathrm{~mm})$ of each CSCspost system was sectioned using a low-speed diamond saw (Isomet 1000, Beuhler Ltd., Lake Bluff, IL, USA) that resulted in 5 discs ( $\mathrm{n}=50$ discs/subgroup). The push-out bond strength of each disc was tested using a universal testing machine (Model TT-B, Instron Co., Canton, MA, USA) and loaded with a cylindrical plunger $(1 \mathrm{~mm}$ diameter) at $0.05 \mathrm{~mm} / \mathrm{min}$ cross-head speed. The pushout bond strength $(\mathrm{MPa})$ was calculated by dividing the load at failure (Newtons) by the bonding area $\left(\mathrm{mm}^{2}\right)$. The bonding area was calculated using the following equation [22]:

$$
A=2 r \times \pi \times h
$$

where $r$ is the post radius, $h$ is the thickness of each post section, and $\pi$ is the constant 3.14.

\section{Failure mode analysis}

The debonded specimens were observed by stereomicroscope (ZEISS, Stemi 2000-C, Oberkochen, Germany) at
$50 \times$ for analyzing the failure pattern. Failure mode was classified as Type 1; adhesive failure between the CSCs and the post, Type 2; cohesive failure within the post, Type 3; cohesive failure within the CSCs, and Type 4; mixed failure [23]. The failure mode was evaluated by the same operator.

\section{Surface topography}

A total of 20 specimens of each type of post ( $n=5 /$ group) were prepared and grouped as mentioned before. The specimens were sputter-coated with gold (Sputter Coater S 150A; Edwards, Crawley, England). A scanning electron microscope (JSM $5600 \mathrm{Lv}$ JEOL, Tokyo, Japan) was used to characterize the surface topography of the specimens at magnifications of $500 \times$.

\section{Statistical analysis}

Normality of data distribution was tested using Kolmogorov-Smirnov and the equality of variances with the Levene's test. The data were normally distributed. Data of push-out bond strength were statistically analyzed (SPSS 22.0 software; IBM Corp., Armonk, NY, USA) using three-way ANOVA based on three factors (the type of post, type of treatment, and type of CSCs) and their interactions. Multiple comparisons were conducted by the Tukey's test. The level of statistical significance was set at $P<0.05$. A Weibull analysis (SuperSMITH software; Fulton Findings, Torrance, CA, USA) was performed on the push-out bond strength data.

\section{Results}

Table 2 showed the results of 3-way ANOVA. The push-out bond strength was significantly influenced by the type of post, type of surface treatment, and type of CSCs $(P<0.001)$. The RP revealed higher bond strength to CSCs than RX $(P<0.001)$. Regarding the type of CSCs, the BD showed higher bond strength than WMTA $(P<0.001)$. There was no significant interaction

Table 2 Three-way ANOVA for the type of post, type of surface treatment, type of CSCs, and the interaction terms according to pushout bond strength data

\begin{tabular}{|c|c|c|c|c|c|}
\hline Source of variation & Sum of squares & Df & Mean squares & $\mathrm{F}$ & $P$ value \\
\hline Type of post & 136.951 & 1 & 136.951 & 166.987 & $<0.001$ \\
\hline Type of surface treatment & 646.197 & 3 & 215.399 & 262.639 & $<0.001$ \\
\hline Type of CSCS & 172.608 & 1 & 172.608 & 210.464 & $<0.001$ \\
\hline Post type $\times$ CSCs type & 2.122 & 1 & 2.122 & 2.587 & 0.108 \\
\hline Post type $\times$ surface treatment & 12.314 & 3 & 4.105 & 5.005 & 0.002 \\
\hline CSCs type $\times$ surface treatment & 2.451 & 3 & 0.817 & 0.996 & 0.394 \\
\hline Post type $\times$ CSCs type $\times$ surface treatment & 2.941 & 3 & 0.980 & 1.195 & 0.311 \\
\hline Total & $13,290.960$ & 800 & & & \\
\hline
\end{tabular}

Statistically significant difference at $P<0.05$ 
between type of post and type of CSCs $(P=0.108)$ and between the type of CSCs and type of treatment $(P=0.394)$. There was a significant interaction between the type of post and type of treatment $(P=0.002)$. There was no significant interaction between type of post, type of CSCs, and type of treatment $(P=0.311)$. The mean and standard deviations of push-out bond strength $(\mathrm{MPa})$ are presented in Table 3 . The pushout bond strength for posts treated with $\mathrm{TiF}_{4} 4 \mathrm{wt} / \mathrm{v} \%$ showed greater bond strength than the other surface treatments $(P<0.05)$. The improvement in the bond strength according to the surface treatments was as follows: $\mathrm{TiF}_{4} 4 \mathrm{wt} / \mathrm{v} \%>\mathrm{HF}>\mathrm{SB}>\mathrm{C}$. Failure mode analysis of different groups is presented in Fig. 1. The higher percentage of failure modes was the adhesive failure between the post and CSCs (69.5\%; Type 1). The other types of failure modes including mixed failures (17.7\%; Type 4), cohesive failure within the CSCs (8.9\%; Type 3 ), and cohesive failure within the post (3.9\%; Type 2).

The data of Weibull analysis of different groups are presented in Table 4 . The BD/RP-TiF 4 wt/v\% showed the greater characteristic bond strength $\left(\sigma_{0}\right)(15.93)$ than the other groups. The surface treatment with $\mathrm{TiF}_{4}$ $4 \mathrm{wt} / \mathrm{v} \%$ had more reliability than the other treatments (Table 4 and Fig. 2). The Weibull plot for different groups is presented in Fig. 2.

Representative SEM photomicrographs for the surface microstructure of the different post systems with different treatments are shown in Fig. 3. The untreated RP showed exposed glass fibers with rather a rough surface than RX post that was typically more covered by the resin matrix (Fig. 3a, e; respectively). The sandblasted groups exhibited fractured glass fibers (Fig. 3b, $f$; respectively). For the RP post, the HF surface treatment caused cracks in the glass fiber (Fig. 3c). For the RX post, the glass fibers were exposed with HF surface treatment (Fig. 3g). The $\mathrm{TiF}_{4} 4 \mathrm{wt} / \mathrm{v} \%$ surface treatments exposed the glass fibers of the RP and RX posts (Fig. 3d, h; respectively).

Table 3 Mean (standard deviation) values and statistical analysis of push-out bond strength (MPa) of different CSCs/post systems with different surface treatments

\begin{tabular}{lllll}
\hline Surface treatment & \multicolumn{4}{l}{ CSCs/post systems } \\
\cline { 2 - 5 } & BD/RP & BD/RX & WMTA/RP & WMTA/RX \\
\hline $\mathrm{C}$ & $3.34(0.78)^{\mathrm{D}}$ & $2.73(0.59)^{\mathrm{D}}$ & $2.43(0.59)^{\mathrm{D}}$ & $2.13(0.46)^{\mathrm{D}}$ \\
$\mathrm{SB}$ & $4.38(1.09)^{\mathrm{C}}$ & $3.35(1.01)^{\mathrm{C}}$ & $3.12(0.49)^{\mathrm{C}}$ & $2.65(0.73)^{\mathrm{C}}$ \\
$\mathrm{HF}$ & $5.12(1.12)^{\mathrm{B}}$ & $4.13(1.11)^{\mathrm{B}}$ & $4.23(0.95)^{\mathrm{B}}$ & $3.19(0.96)^{\mathrm{B}}$ \\
$\mathrm{TiF}_{4} 4 \mathrm{wt} / \mathrm{v} \%$ & $6.15(1.03)^{\mathrm{A}}$ & $5.05(1.05)^{\mathrm{A}}$ & $5.08(1.05)^{\mathrm{A}}$ & $3.99(0.99)^{\mathrm{A}}$ \\
\hline
\end{tabular}

Mean values represented with different superscript uppercase letter (column) are significantly different $(P<0.05)$

\section{Discussion}

The present study evaluated the effect of surface treatment on bond strength of CSCs materials to fiber posts. The findings showed that the adhesion was considerably affected by the type of post, type of surface treatments, and type of CSCs. Accordingly, the null hypothesis was rejected.

It is significant to enhance bonding between CSCs and fiber posts to reinforce the root canals for treating nonvital immature permanent teeth [4]. In the present study, a cylindrical plastic matrix was used instead of a root specimen for testing the bond strength as the purpose of the study was to assess the bond strength between the posts and CSBs. There are limitations of using root dentin to test adhesion with fiber post including variation in hardness, elastic modulus, flexural strength, geometric parameters among different teeth that may affect the bond strength measurements [27, 28]. Consequently, specimens from the post and CSBs were prepared to test the adhesion between them without another factor that may affect the outcomes. All tested groups were subjected to thermocycling to simulate the clinical conditions that might provide a possible prediction of bonding durability [23]. It was postulated that approximately 10,000 thermal cycles correspond to 1 year of clinical function [26]. In the present study, $\mathrm{TiF}_{4} 4 \mathrm{wt} / \mathrm{v} \%$ was used because it was shown in a previous study that this concentration enhanced the bond strength of resin cement to a fiber post [23]. Similarly, surface treatment of RP and RX posts with $\mathrm{TiF}_{4} 4 \mathrm{wt} / \mathrm{v} \%$ for 4 min revealed greater bond strength to CSCs than the other treatments. This could be explained that $\mathrm{TiF}_{4} 4 \mathrm{wt} / \mathrm{v} \%$ treatment might remove the surface layer of resin of the post which allows further areas for micromechanical retention with the CSCs $[22,23]$. The $\mathrm{TiF}_{4} 4 \mathrm{wt} / \mathrm{v} \%$ surface treatments exposed the glass fibers of the posts (Fig. 3d, h; respectively). In addition, surface treatments of fiber posts with $\mathrm{TiF}_{4} 4 \mathrm{wt} / \mathrm{v} \%$ showed higher percentages of mixed failure modes (Type 4) than the other types of surface treatment.

The surface treatment with HF showed higher bond strength of CSCs to fiber posts than SB and C groups. The HF surface treatment might modify the outer surface layer of the fiber post without compromising the strength properties of the post $[23,25]$. It was observed that HF surface treatment caused some cracks in RP post and the glass fibers were exposed in RX post (Fig. 3c, g; respectively). It was reported that HF surface treatment had a destructive effect on the surface integrity of the fiber post $[29,30]$.

Roughening the surface of fiber post with tribochemical silica coating might enhance the bond strength with the other bonded materials due to mechanical retention $[23,31]$. Surface roughness with sandblasting increased 


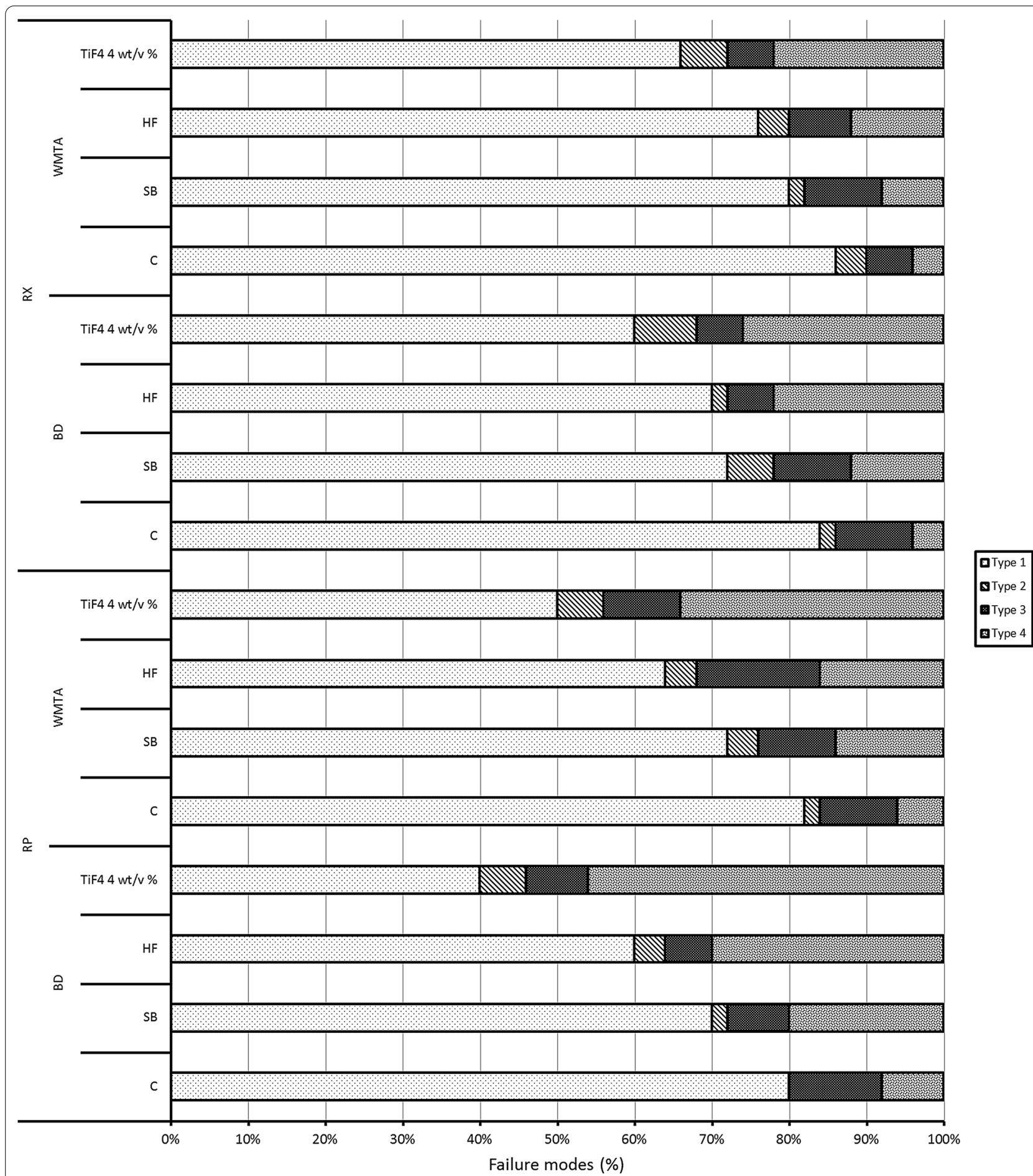

Fig. 1 Failure modes distribution of different groups. Type 1; adhesive failure between the CSCs and the post, Type 2; cohesive failure within the post, Type 3; cohesive failure within the CSCs, and Type 4; mixed failure

the surface area of exposed glass fibers for bonding with the CSCs and accordingly enhancing the bond strength $[23,31]$. Fiber posts that did not receive surface treatments showed the lowest bond strength with CSCs compared with the other groups. This finding indicates the importance of surface modifications of fiber posts to enhance the adhesion with CSCs. 
Table 4 Weibull analysis of push-out bond strength (MPa) of different CSCs/post systems with different surface treatments

\begin{tabular}{|c|c|c|c|c|c|c|c|c|}
\hline \multirow[t]{3}{*}{ Surface treatment } & \multicolumn{8}{|c|}{ CSCs/post systems } \\
\hline & \multicolumn{2}{|l|}{$\mathrm{BD} / \mathrm{RP}$} & \multicolumn{2}{|l|}{$\mathrm{BD} / \mathrm{RX}$} & \multicolumn{2}{|l|}{ WMTA/RP } & \multicolumn{2}{|l|}{ WMTA/RX } \\
\hline & $\begin{array}{l}\text { Weibull } \\
\text { modulus } \\
\text { (m) }\end{array}$ & $\begin{array}{l}\text { Characteristic } \\
\text { bond strength } \\
\left(\sigma_{0}\right)\end{array}$ & $\begin{array}{l}\text { Weibull } \\
\text { modulus } \\
(\mathrm{m})\end{array}$ & $\begin{array}{l}\text { Characteristic } \\
\text { bond strength } \\
\left(\sigma_{0}\right)\end{array}$ & $\begin{array}{l}\text { Weibull } \\
\text { modulus } \\
(\mathrm{m})\end{array}$ & $\begin{array}{l}\text { Characteristic } \\
\text { bond strength } \\
\left(\sigma_{0}\right)\end{array}$ & $\begin{array}{l}\text { Weibull } \\
\text { modulus } \\
\text { (m) }\end{array}$ & $\begin{array}{l}\text { Characteristic } \\
\text { bond strength } \\
\left(\sigma_{0}\right)\end{array}$ \\
\hline C & 2.63 & 8.31 & 3.78 & 6.5 & 3.24 & 6.65 & 3.15 & 5.54 \\
\hline SB & 2.74 & 11.41 & 2.56 & 8.54 & 3.87 & 7.59 & 4.25 & 4.31 \\
\hline $\mathrm{HF}$ & 2.8 & 12.9 & 2.53 & 10.42 & 3.22 & 10.86 & 3.22 & 5.64 \\
\hline $\mathrm{TiF}_{4} 4 \mathrm{wt} / \mathrm{v} \%$ & 3.02 & 15.93 & 2.81 & 12.91 & 3.89 & 12.23 & 3.46 & 6.77 \\
\hline
\end{tabular}

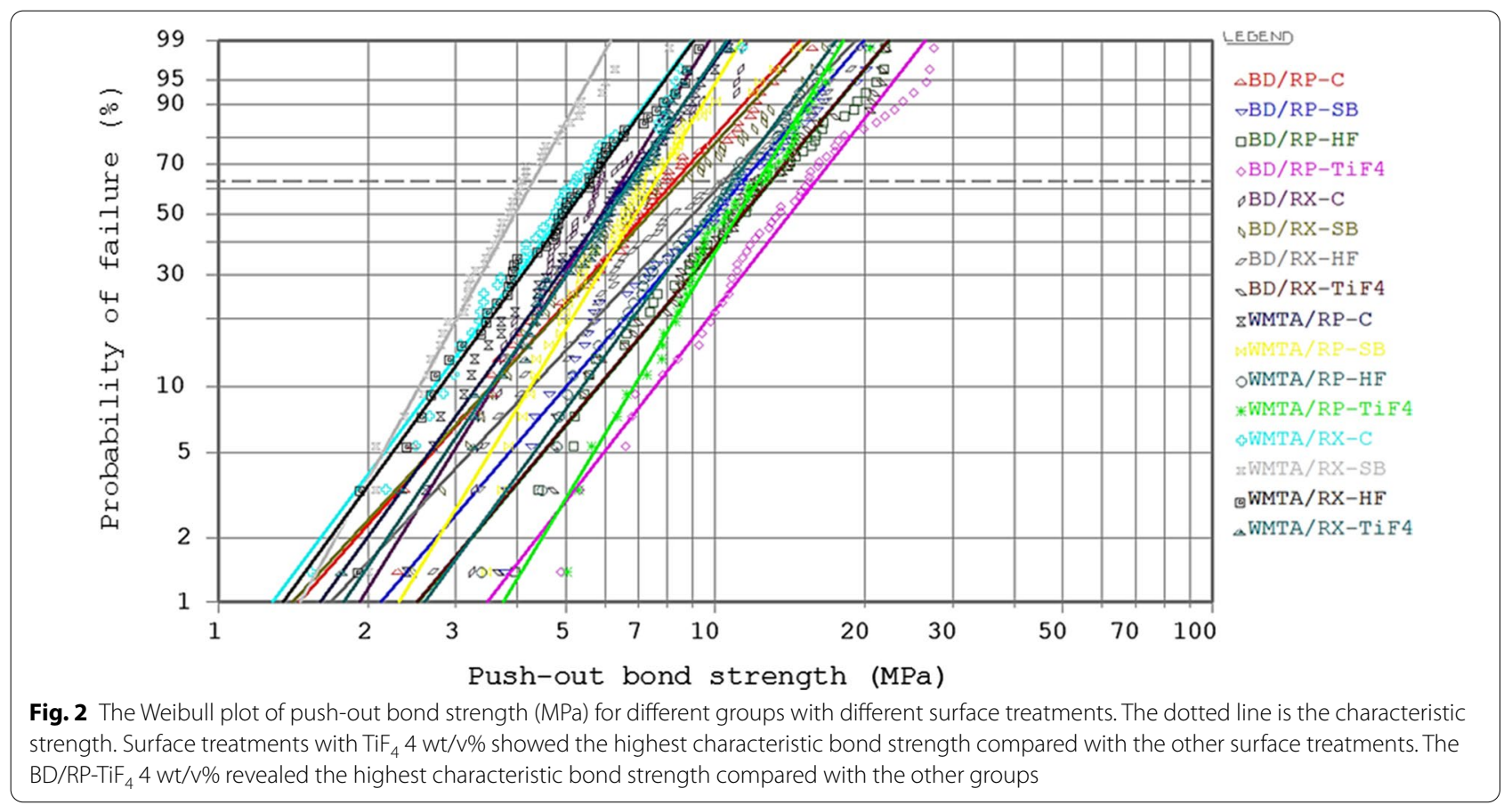

The RP showed higher bond strength with CSCs than the RX post. This finding could be attributed to the different surface topography between RP and RX posts [22]. The surface topography of RP showed a relatively uneven surface with some uncovered glass fibers as shown in the control group (Fig. 3a) which provides more surface areas for mechanical retention with CSCs. The RP is composed of $70 \%$ glass fiber, $10 \%$ filler, and $20 \%$ urethane dimethacrylate [23]. However, the surface of the RX post was typically more enclosed by the resin matrix (Fig. 3e). The RX post is composed of glass fiber reinforced composite and methacrylate resin [22]. The differences in the composition of posts might influence their bond strength with the CSCs.
The $\mathrm{BD}$ revealed higher bond strength with $\mathrm{RP}$ and RX posts than WMTA. This enhancement in the bond strength might be due to the improved physical properties and the integrity of $\mathrm{BD}[5,32]$ that might improve the bonding with the glass fiber posts. It had been reported that $\mathrm{BD}$ had a higher resistance to dislodgement than WMTA [32]. It could be postulated that BD had better mechanical adhesion with the posts after surface treatment that interlocks mechanically within the surface irregularities. CSCs materials should have adequate adaptation and a consistent adhesion to the post surface to reinforce the roots for treating non-vital immature permanent teeth [4]. 

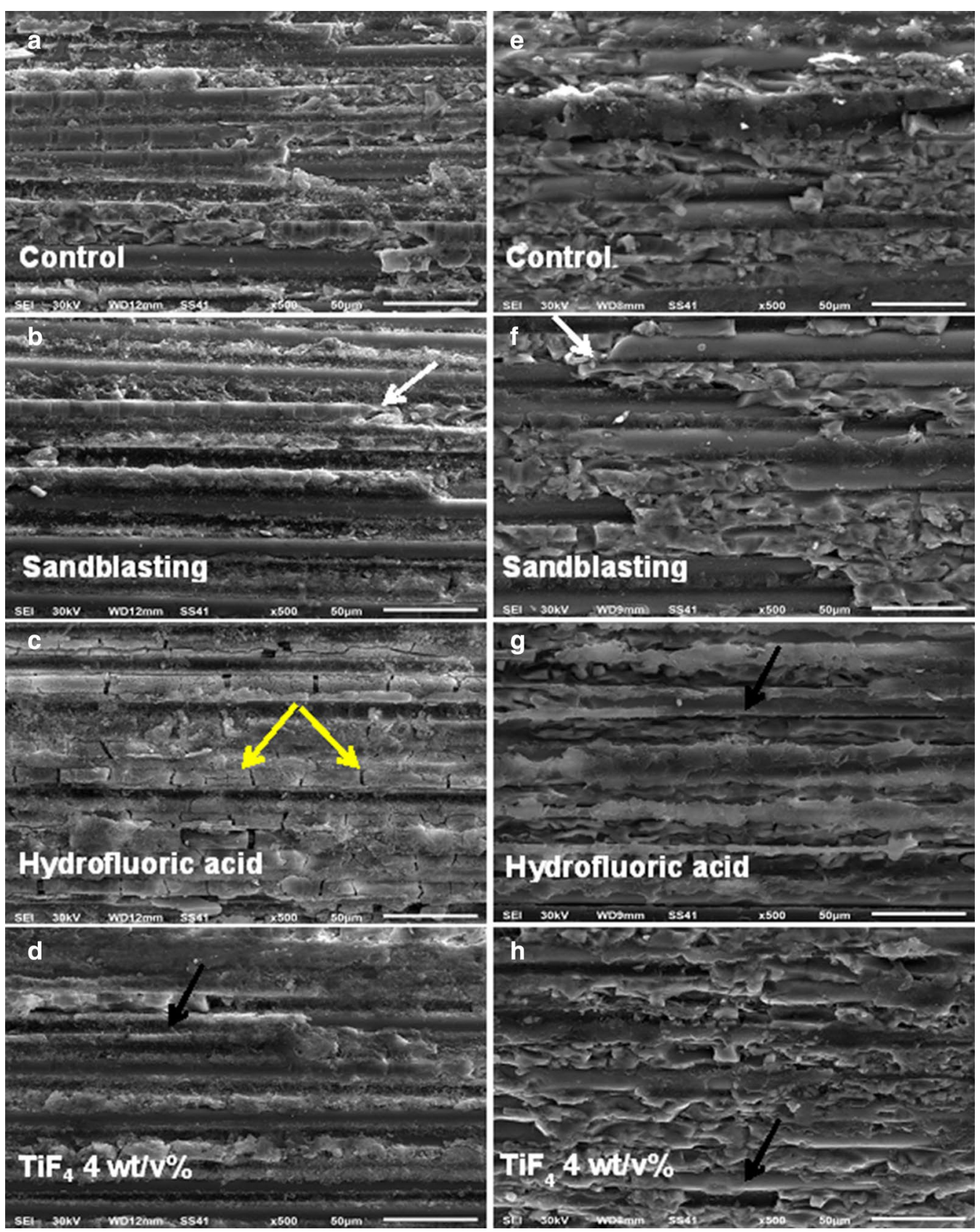

Fig. 3 Representative SEM photomicrographs ( $\times 500$ ) for the surface microstructure of $\mathbf{a}-\mathbf{d}$ RP and $\mathbf{e}-\mathbf{h}$ RX posts; respectively with different treatments. White arrows showed fractured glass fibers, yellow arrows showed the cracks in the glass fibers, and the black arrows showed the exposed glass fibers

The Weibull analysis was conducted on the push-out bond strength data. The BD/RP-TiF 4 wt/v\% showed higher characteristic bond strength $\left(\sigma_{0}\right)$ than the other groups, comparable to the bond strength data. It was observed that $\mathrm{TiF}_{4} 4 \mathrm{wt} / \mathrm{v} \%$ surface treatment had more reliability than the other treatments. It could be postulated that the clinical relevance of fiber post surface treatment with $\mathrm{TiF}_{4} 4 \mathrm{wt} / \mathrm{v} \%$ might improve the bond strength with CSCs. One of the limitations of the present study is to mimic the clinical conditions in practice for restoring endodontic treated teeth with CSBs and glass fiber post. In addition, other parameters existing in the oral environment such as fatigue loading, temperature changes, and constant moisture could influence the 
performance of glass fiber post and CSBs. Due to the limitations of in vitro studies, further clinical studies are essential to assess the performance of treated glass fiber posts with the CSCs to restore endodontic treated teeth to give reliable recommendations for dental practitioners.

\section{Conclusions}

$\mathrm{BD}$ revealed higher bond strength to fiber posts than WMTA. The $\mathrm{TiF}_{4} 4 \mathrm{wt} / \mathrm{v} \%$ surface treatment enhanced the bond strength of BD and WMTA to glass fiber posts than the other treatments. The RP post improved the bond strength to CSCs than RX posts.

\section{Abbreviations}

BD: Biodentine; CSCs: Calcium silicate-based cements; $\sigma_{0}$ : Characteristic bond strength; C: Control; HF: Hydrofluoric acid; RP: Reblida post; RX: RelyX post; SB: Sandblasting; WMTA: White mineral trioxide aggregate.

\section{Acknowledgements}

The authors deny any conflicts of interest related to this study.

\section{Authors' contributions}

$\mathrm{AME}, \mathrm{SE}, \mathrm{AM}, \mathrm{AH}$, and $\mathrm{AE}$ were responsible for the concept, design and implementation of the work, analyzed the participant data and interpretation of data. AME and SE were major contributors in writing the manuscript. All authors read and approved the final manuscript.

\section{Funding}

This study was supported by the Taif University Researchers Supporting Project number (TURSP-2020/256) Taif University, Taif, Saudi Arabia.

\section{Availability of data and materials}

The datasets generated and analyzed during the current study are not publicly available due to (ownership of data) but are available from the corresponding author on reasonable request.

\section{Declarations}

Ethics approval and consent to participate

Not applicable.

\section{Consent for publication}

Not applicable.

\section{Competing interests}

The authors declare that they have no competing interests.

\section{Author details}

1 Department of Endodontics, Faculty of Dentistry, Mansoura University, Mansoura 35516, Egypt. ${ }^{2}$ Department of Restorative and Dental Materials, Faculty of Dentistry, Taif University P.O Box 11099, Taif 21944, Saudi Arabia. ${ }^{3}$ Department of Orthodontics, Faculty of Dentistry, King Abdulaziz University, Jeddah, Saudi Arabia. ${ }^{4}$ Department of Restorative Dental Sciences, Vision Colleges, Jeddah, Saudi Arabia. ${ }^{5}$ Department of Dental Biomaterials, Faculty of Dentistry, Mansoura University, Mansoura, Egypt.

Received: 7 December 2020 Accepted: 15 March 2021

Published online: 19 March 2021

\section{References}

1. Parirokh M, Torabinejad M. Mineral trioxide aggregate: a comprehensive literature review—part III: clinical applications, drawbacks, and mechanism of action. J Endod. 2010;36(3):400-13. https://doi.org/10. 1016/j.joen.2009.09.009.

2. Bogen $\mathrm{G}$, Kuttler $\mathrm{S}$. Mineral trioxide aggregate obturation: a review and case series. J Endod. 2009;35(6):777-90. https://doi.org/10.1016/j.joen. 2009.03.006.

3. El-Ma'aita AM, Qualtrough AJ, Watts DC. The effect of smear layer on the push-out bond strength of root canal calcium silicate cements. Dent Mater. 2013;29(7):797-803. https://doi.org/10.1016/j.dental.2013.04.020.

4. Elnaghy A, Elsaka S. Fracture resistance of simulated immature roots using Biodentine and fiber post compared with different canal-filling materials under aging conditions. Clin Oral Investig. 2020;24(3):1333-8.

5. Grech L, Mallia B, Camilleri J. Investigation of the physical properties of tricalcium silicate cement-based root-end filling materials. Dent Mater. 2013;29(2):e20-28. https://doi.org/10.1016/j.dental.2012.11.007.

6. Küçükkaya Eren S, Aksel H, Askerbeyli Örs S, Serper A, Koçak Y, Ocak M, et al. Obturation quality of calcium silicate-based cements placed with different techniques in teeth with perforating internal root resorption: a micro-computed tomographic study. Clin Oral Investig. 2019;23(2):80511. https://doi.org/10.1007/s00784-018-2502-2.

7. Schmoldt SJ, KirkpatrickTC, Rutledge RE, Yaccino JM. Reinforcement of simulated immature roots restored with composite resin, mineral trioxide aggregate, gutta-percha, or a fiber post after thermocycling. J Endod. 2011;37(10):1390-3. https://doi.org/10.1016/j.joen.2011.07.001.

8. Yoldas SE, Bani M, Atabek D, Bodur H. Comparison of the potential discoloration effect of Bioaggregate, Biodentine, and White Mineral Trioxide Aggregate on bovine teeth: in vitro research. J Endod. 2016;42(12):18158. https://doi.org/10.1016/j.joen.2016.08.020.

9. Alazrag MA, Abu-Seida AM, El-Batouty KM, El Ashry SH. Marginal adaptation, solubility and biocompatibility of TheraCal LC compared with MTAangelus and biodentine as a furcation perforation repair material. BMC Oral Health. 2020;20(1):298. https://doi.org/10.1186/s12903-020-01289-y.

10. Camilleri J, Formosa L, Damidot D. The setting characteristics of MTA Plus in different environmental conditions. Int Endod J. 2013;46(9):831-40. https://doi.org/10.1111/iej.12068.

11. Kang SH, Shin YS, Lee HS, Kim SO, Shin Y, Jung IY, et al. Color changes of teeth after treatment with various mineral trioxide aggregate-based materials: an ex vivo study. J Endod. 2015;41(5):737-41. https://doi.org/ 10.1016/j.joen.2015.01.019.

12. Torabinejad M, Parirokh M. Mineral trioxide aggregate: a comprehensive literature review — part II: leakage and biocompatibility investigations. J Endod. 2010;36(2):190-202. https://doi.org/10.1016/j.joen.2009.09.010.

13. Linsuwanont P, Kulvitit S, Santiwong B. Reinforcement of simulated immature permanent teeth after mineral trioxide aggregate apexification. J Endod. 2018;44(1):163-7. https://doi.org/10.1016/j.joen.2017.08. 031.

14. Alonso de la Pena V, Darriba IL, Caserio Valea M, Guitian RF. Mechanical properties related to the microstructure of seven different fiber reinforced composite posts. J Adv Prosthodont. 2016;8(6):433-8. https://doi. org/10.4047/jap.2016.8.6.433.

15. Frater M, Forster A, Jantyik A, Braunitzer G, Nagy K, Grandini S. In vitro fracture resistance of premolar teeth restored with fibre-reinforced composite posts using a single or a multi-post technique. Aust Endod J. 2017:43(1):16-22. https://doi.org/10.1111/aej.12150

16. Soares CJ, Soares PV, de Freitas Santos-Filho PC, Castro CG, Magalhaes $D$, Versluis $A$. The influence of cavity design and glass fiber posts on biomechanical behavior of endodontically treated premolars. J Endod. 2008;34(8):1015-9. https://doi.org/10.1016/j.joen.2008.05.017.

17. Xie W, Yang S, Hai Q, Wang J. Effect of Ferrule Thickness on Fracture Resistance of Endodontically Treated Incisors Restored with Fiber Post and Metal Crown. Int J Prosthodont. 2020;33(3):321-7. https://doi.org/10 11607/ijp.6423.

18. Choi Y, Pae A, Park EJ, Wright RF. The effect of surface treatment of fiberreinforced posts on adhesion of a resin-based luting agent. J Prosthet Dent. 2010;103(6):362-8. https://doi.org/10.1016/S0022-3913(10)60078-9.

19. Elnaghy AM, Elsaka SE. Effect of surface treatments on the flexural properties and adhesion of glass fiber-reinforced composite post to selfadhesive luting agent and radicular dentin. Odontology. 2016;104(1):607. https://doi.org/10.1007/s10266-014-0184-z.

20. Arisu HD, Kivanc BH, Saglam BC, Simsek E, Gorgul G. Effect of post-space treatments on the push-out bond strength and failure modes of glass 
fibre posts. Aust Endod J. 2013;39(1):19-24. https://doi.org/10.1111/j. 1747-4477.2010.00275.x.

21. Sumitha M, Kothandaraman R, Sekar M. Evaluation of post-surface conditioning to improve interfacial adhesion in post-core restorations. J Conserv Dent. 2011;14(1):28-31. https://doi.org/10.4103/0972-0707. 80728.

22. Elsaka SE. Influence of chemical surface treatments on adhesion of fiber posts to composite resin core materials. Dent Mater. 2013;29(5):550-8. https://doi.org/10.1016/j.dental.2013.03.004.

23. Elsaka SE, Elnaghy AM. Bonding durability of titanium tetrafluoride treated glass fiber post with resin cement. Dent Mater J. 2019;38(2):18995. https://doi.org/10.4012/dmj.2018-054.

24. Goracci C, Raffaelli O, Monticelli F, Balleri B, Bertelli E, Ferrari M. The adhesion between prefabricated FRC posts and composite resin cores: microtensile bond strength with and without post-silanization. Dent Mater. 2005;21(5):437-44. https://doi.org/10.1016/j.dental.2004.07.012

25. Aksornmuang J, Chuenarrom C, Chittithaworn N. Effects of various etching protocols on the flexural properties and surface topography of fiber-reinforced composite dental posts. Dent Mater J. 2017;36(5):614-21. https://doi.org/10.4012/dmj.2016-290.

26. Morresi AL, D'Amario M, Capogreco M, Gatto R, Marzo G, D'Arcangelo C, et al. Thermal cycling for restorative materials: does a standardized protocol exist in laboratory testing? A literature review. J Mech Behav Biomed Mater. 2014;29:295-308. https://doi.org/10.1016/j.jmbbm.2013.09.013.

27. Chen WP, Chen YY, Huang SH, Lin CP. Limitations of push-out test in bond strength measurement. J Endod. 2013;39(2):283-7. https://doi.org/10. 1016/j.joen.2012.11.002
28. Schwartz RS. Adhesive dentistry and endodontics. Part 2: bonding in the root canal system-the promise and the problems: a review. J Endod. 2006;32(12):1125-34. https://doi.org/10.1016/j.joen.2006.08.003.

29. Valandro LF, Yoshiga S, de Melo RM, Galhano GAP, Mallmann A, Marinho $\mathrm{CP}$, et al. Microtensile bond strength between a quartz fiber post and a resin cement: effect of post surface conditioning. J Adhes Dent. 2006;8(2):105-11.

30. Sahafi A, Peutzfeld A, Asmussen E, Gotfredsen K. Effect of surface treatment of prefabricated posts on bonding of resin cement. Oper Dent. 2004;29(1):60-8.

31. Cekic-Nagas I, Sukuroglu E, Canay S. Does the surface treatment affect the bond strength of various fibre-post systems to resin-core materials? J Dent. 2011;39(2):171-9. https://doi.org/10.1016/j.jdent.2010.11.008.

32. De-Deus G, Ferreira CB, Oliveira Dda S, de QueirozTF, Souza EM, de Gouvêa $C V$, et al. Resistance of hydraulic calcium silicate cements to dislodgment in short- and long-term assessment. J Adhes Dent. 2016;18(2):15760. https://doi.org/10.3290/j.jad.a35840.

\section{Publisher's Note}

Springer Nature remains neutral with regard to jurisdictional claims in published maps and institutional affiliations.
Ready to submit your research? Choose BMC and benefit from:

- fast, convenient online submission

- thorough peer review by experienced researchers in your field

- rapid publication on acceptance

- support for research data, including large and complex data types

- gold Open Access which fosters wider collaboration and increased citations

- maximum visibility for your research: over 100M website views per year

At BMC, research is always in progress.

Learn more biomedcentral.com/submissions 